\title{
The comparative burden of salmonellosis in the European Union member states, associated and candidate countries
} Birgitta de Jong* ${ }^{* 1,2}$ and Karl Ekdahl ${ }^{\dagger 2,3}$

\author{
Address: ${ }^{1}$ Department of Epidemiology, Swedish Institute for Infectious Disease Control (SMI), Solna, Sweden, ${ }^{2}$ Department of Medical \\ Epidemiology and Biostatistics, Karolinska Institute, Stockholm, Sweden and ${ }^{3}$ European Centre for Disease Prevention and Control (ECDC), \\ Stockholm, Sweden \\ Email: Birgitta de Jong* - birgitta.dejong@sll.se; Karl Ekdahl - karl.ekdahl@ecdc.eu.int \\ * Corresponding author †Equal contributors
}

Published: 10 January 2006

BMC Public Health 2006, 6:4 doi:10.1 186/147/-2458-6-4

This article is available from: http://www.biomedcentral.com/I47I-2458/6/4

(C) 2006 de Jong and Ekdahl; licensee BioMed Central Ltd.

This is an Open Access article distributed under the terms of the Creative Commons Attribution License (http://creativecommons.org/licenses/by/2.0), which permits unrestricted use, distribution, and reproduction in any medium, provided the original work is properly cited.
Received: II October 2005

Accepted: 10 January 2006

\begin{abstract}
Background: Salmonella is an infectious agents causing numerous cases of illness each year, and thereby having significant economic impact. Using returning Swedish travellers we estimated the burden of salmonellosis in different European countries.

Methods: From the Swedish database on notifiable communicable diseases 15,864 cases with travel-associated salmonellosis acquired in Europe from 1997-2003 were retrieved. These cases were compared to a dataset from the same years on $14,17 \mid$ randomly selected Swedish residents, with a history of recent overnight travel in Europe. Distribution of salmonellosis in returning travellers and the distribution of Salmonella Enteritidis was analysed for different member states in the European Union, associated and candidate countries. The risk of being notified with a salmonella infection after return from each European country/region was calculated, and compared with official reporting data rom these countries. Using Norway as reference country, we could I) construct comparable incidence estimates and 2) calculate the "under-reporting" in each country compared to Norway.
\end{abstract}

Results: The highest burden of salmonellosis was estimated for Bulgaria (274I//00,000), followed by Turkey with 2344/100 000 and Malta with 2141/100 000. S. Enteritidis is the dominating serotype, $66.9 \%$ of all cases and phage type 4 accounts for $37.5 \%$ of the $S$. Enteritidis cases

Conclusion: Using returning tourists as a sentinel population can provide a useful base for comparison of disease burdens in different countries/regions. Focusing prevention of salmonellosis to prevention of egg and poultry associated S. Enteritidis infection will have a major impact from a public health perspective and will significantly lower the burden of disease in most European countries.

\section{Background}

Salmonellosis is an important public health problem causing substantial morbidity, and thus also having a significant economic impact. Although most infections cause mild to moderate self-limited disease, serious infec- tions leading to death do occur. In the United States it is estimated that 1.4 million non-typhoidal Salmonella infections with 400 deaths occurs annually [1]. Calculations from England and Wales regarding year 1995 
resulted in an estimate of 102,227 indigenous cases, with 3,412 hospital admissions and 268 deaths [2].

The infective dose is usually high, but the bacteria grow well in most foodstuff. In food with a high fat content, e.g. chocolate and cheese, the infective dose is very low, and just a few bacteria may be sufficient to cause infection $[3,4]$. The susceptibility to infection varies; in infants, elderly, or compromised hosts, the critical infective dose is lower [5]. The onset of disease is often acute with diarrhoea, nausea and vomiting [6]. The incubation period is $1-3$ (range $<1-10$ ) days. The carrier state is normally 4-6 weeks, but a few percent may be asymptomatic carriers for months or even years $[3,7]$. No vaccine is available against non-typhoidal salmonellosis. Using the KauffmannWhite scheme for antisera reaction to different bacterial $\mathrm{O}$ and $\mathrm{H}$ antigens, more than 2,500 Salmonella serovars have been identified, with prevalence patterns varying between different parts of the world $[8,9]$. In Europe $S$. Enteritidis has been the most reported serovar since the middle of the 1980 s [10]. In the developed world salmonellosis due to $S$. Enteritidis is most often associated with consumption of poultry and eggs $[11,12]$.

The European Union (EU) consists of 25 member states along with 4 associated EEA/ EFTA (European Economic Area/ European Free Trade Area) countries and 4 candidate countries, with altogether 630 millions inhabitants. The recent establishment of the European Centre for Disease Prevention and Control (ECDC), shows that control and prevention of communicable diseases are high on the EU political agenda. The Salmonella species is one of the eight micro-organisms in the EU Zoonoses Monitoring Directive (2003/99/EG), which is mandatory to always monitor [13]. The subject matter and scope of this directive is to ensure that zoonoses are properly monitored and that foodborne outbreaks receive proper epidemiological investigation, to enable the collection in the EU of the relevant information necessary to evaluate trends and sources. In the Zoonosis Control Regulation (2160/2003) which regulates the control of salmonella and other specified foodborne zoonotic agents, salmonella is the only agent specified [14]. This directive and regulations shows that salmonellosis is a disease considered to have a high impact on the human health in the EU. However, public health actions need to be based on best possible surveillance data, but the ability to detect and report enteric zoonoses varies considerably between the European countries, hampering meaningful comparisons between countries [15].

In this study we are using Swedish notification data on all cases of salmonellosis, who acquired the infection during travel in Europe, and a unique database on travel patterns to give an estimate of the comparative burden of nontyphoidal salmonellosis in different European countries.

\section{Methods}

\section{Notification data on salmonellosis}

The statutory notification of salmonellosis in Sweden is regulated in the Communicable Disease Act. All notifications are submitted to the Swedish Institute for Infectious Disease Control (SMI), both by the physician having seen the patient (clinical notification) and by the laboratory having diagnosed the causative agent (laboratory notification). The clinical notifications include information of epidemiological relevance, e.g. route of infection, risk group, and likely place and country of infection. The laboratory notifications include the Salmonella serovar and if a $S$. Enteritidis or $S$. Typhimurium, phage types are included. The clinical and laboratory reports for each patient are merged, using a unique personal identification number. The personal identification number is used in all contacts with the health care, both private and public.

For this study, notification data for the period January 1997 to December 2003 were used. All records in the national surveillance database concerning patients notified with salmonellosis were retrieved. The clinical notification has the information in which country the patient has acquired the infection and this information was used to judge if the patient was a case of travel associated salmonellosis or not. Patients with stated indigenously acquired infection (i.e. infected in Sweden) or patients for which information on likely country of infection was either missing or "unknown" were excluded. Also patients with a travel history outside Europe were excluded. Furthermore, the dataset was "cleaned" from infections in recently arrived immigrants, refugees and non-Swedish visitors (identified through the personal identification number).

\section{Travel patterns}

As denominator on travel patterns, a commercial database, the Tourist Database (TDB) was used [16]. This dataset is based on a randomized selection of 2,000 persons of the Swedish population every month. These persons are telephone interviewed with questions on both business and pleasure travel during last month, and the data weighted and extrapolated to give an estimate of the total number of Swedish travellers to different destinations. Out of the total database, containing data on almost 170,000 interviews, altogether 14,171 records from respondents with a history of recent overnight travel in Europe were extracted. These 14,171records represents all persons in the TBD, which has been travelling in Europe. Data on country/region of travel was used for analysis. No data on any illness is available from this dataset. 
Table I: Comparison of risk of Salmonella infection in Swedish travellers to national reported incidence and estimated incidence of salmonellosis.

\begin{tabular}{|c|c|c|c|c|c|c|}
\hline Country & $\begin{array}{c}\text { Risk per } 100,000 \\
\text { travellers }(95 \% \\
\mathrm{Cl})\end{array}$ & $\begin{array}{c}\text { Percent S. } \\
\text { Enteritidis } \\
\text { among Swedish } \\
\text { travellers }\end{array}$ & $\begin{array}{c}\text { Percent S. } \\
\text { Typhimurium } \\
\text { among Swedish } \\
\text { travellers }\end{array}$ & $\begin{array}{c}\text { Reported } \\
\text { incidence per } \\
100,000 \\
\text { inhabitant }\end{array}$ & $\begin{array}{c}\text { Under- } \\
\text { detection index }\end{array}$ & $\begin{array}{c}\text { Estimated } \\
\text { incidence per } \\
100,000 \\
\text { inhabitant }\end{array}$ \\
\hline Norway & $0.2(0.11-0.38)$ & 30 & 40 & 3.77 & I.0 (ref.) & 4 \\
\hline Finland & $0.4(0.28-0.58)$ & 29 & 39 & 13.1 & 0.6 & 8 \\
\hline Iceland & $2.2(0.79-6.1)$ & 25 & 75 & 129 & 0.4 & 47 \\
\hline Estonial & $2.6(0.94-7.2)$ & 85 & 2 & 40.6 & 1.3 & 54 \\
\hline Ireland & $3.2(1.8-3.8)$ & 33 & 25 & 16.0 & 4.3 & 69 \\
\hline Denmark & $3.8(3.4-4.3$ & 67 & 15 & 44.4 & 1.8 & 81 \\
\hline Netherlands ${ }^{2}$ & $4.6(3.2-6.6)$ & 71 & 29 & 12.6 & 7.7 & 98 \\
\hline United Kingdom & $5.6(4.8-6.5)$ & 83 & 7 & 27.9 & 4.3 & 119 \\
\hline France & $8.4(7.2-9.7)$ & 59 & 13 & 21.5 & 8.3 & 178 \\
\hline Germany & $8.3(7.4-9.3)$ & 79 & 13 & 96.1 & 1.8 & 177 \\
\hline Austria & $12.0(9.7-14.9)$ & 83 & 2 & 85.6 & 3.0 & 255 \\
\hline Italy & $12.8(|| .2-\mid 4.6)$ & 54 & 18 & 20.6 & 13.1 & 271 \\
\hline Belgium & $13.5(10.0-18.2)$ & 86 & 10 & 153 & 1.9 & 286 \\
\hline Lithuania' & I5.3 (4.5-52.5) & 94 & 0 & 32.5 & 10.0 & 325 \\
\hline Latvia' & $23.9(12.4-46.5)$ & 98 & I & 43.4 & 11.7 & 507 \\
\hline Greece & $39.2(36.4-42.2)$ & 70 & 8 & 8.5 & 97.7 & 833 \\
\hline Croatia & $40.1(32.7-49.1)$ & 85 & 8 & 27.9 & 30.6 & 852 \\
\hline Slovenia & $40.1(32.7-49.1)$ & 50 & 20 & 85.1 & 10.0 & 852 \\
\hline Hungary & $41.8(33.7-51.8)$ & 71 & 34 & 163 & 5.5 & 888 \\
\hline Czech Republic & $54.8(45.5-66.1)$ & 77 & 5 & 391 & 3.0 & 1161 \\
\hline Slovakia & $54.8(45.5-66.1)$ & 94 & 0 & 336 & 3.5 & 1165 \\
\hline Cyprus & $66.0(56.2-77.6)$ & 37 & 15 & 19.7 & 71.2 & 1403 \\
\hline Romania & $68.6(39.5-119)$ & 40 & 31 & 4.4 & 332 & 1457 \\
\hline Spain 3 & $72.0(68.5-75.7)$ & 79 & 7 & 14.9 & 103 & $|53|$ \\
\hline Poland & $76.5(65.5-89.4)$ & 77 & 3 & 100 & 16.2 & 1626 \\
\hline Portugal & $79.9(68.0-93.9)$ & 82 & 7 & 4.49 & 378 & 1697 \\
\hline Malta & $101(69.1-147)$ & 60 & 13 & 23.1 & 92.6 & 2141 \\
\hline Turkey & $110(97.2-125)$ & 48 & 4 & 39.2 & 59.8 & 2344 \\
\hline Bulgaria & $129(103-162)$ & 68 & 17 & 10.1 & 271 & 2741 \\
\hline
\end{tabular}

I Risk per 100,000 travellers calculated on figures from 2002-2003

2 Incidence calculated on $63 \%$ of inhabitants since reported number of cases is from laboratories with a catchments area of $63 \%$ of inhabitants

\section{Serovar typing and phage typing}

Serovar typing of the Salmonella strains was performed by agglutination using antiserum from Reagensia, Stockholm, Sweden. Interpretation of serovars was made according to the latest edition of the Kauffmann-White scheme from the WHO International Reference Laboratory [8]. Phage typing of $S$. Enteritidis was performed according to the Colindale scheme [17]. These results were included in the laboratory notification from the Swedish national salmonella reference laboratory.

\section{Statistical methods}

The risk of disease per 100,000 travellers was calculated using salmonellosis notification data from the actual country/region as numerator and the estimated total numbers of travellers from the TDB as denominator. Data for each country on the reported number of salmonellosis cases were retrieved from WHO Surveillance Program for Control of Foodborne Infections and Intoxications in Europe, $8^{\text {th }}$ report, year 2000, if not other source is stated.
An under-detection index was calculated with Norway as the reference country (the country with the lowest risk of salmonellosis per 100000 Swedish travellers, and a good national reporting system). The under-detection index is calculated by dividing the incidence/100 000 inhabitants in the country with the risk/100 000 Swedish travellers who visited the country and this quotient is then dived with the quotient from the reference country (Norway). This index denotes estimated number of salmonellosis cases not notified for every notified case. To measure the burden of salmonellosis in each country this index was multiplied with the reported incidence from the actual country. The method, with a detailed discussion on strengths and limitations has been previously published [15].

\section{Ethical considerations}

The TDB contains aggregated data only. Notification data is regulated by the Communicable Disease Act, and contain full personal identification. The subset of the notifi- 


\begin{tabular}{|c|c|c|c|c|c|c|c|c|c|c|c|}
\hline \multirow[b]{2}{*}{ Country } & \multicolumn{11}{|c|}{ Salmonella serovars } \\
\hline & Agona & Blockley & Enteritidis & Hadar & Heidelberg & Infantis & Montevideo & Newport & Saintpaul & Typhimurium & Virchow \\
\hline Norway & & & 3 & & & & & & & 4 & \\
\hline Finland & & & 8 & & & 1 & & & 1 & 11 & 1 \\
\hline Denmark & 2 & & 239 & 4 & 1 & 15 & 2 & 3 & 1 & 53 & 4 \\
\hline Iceland & & & 1 & & & & & & & 3 & \\
\hline Belgium & & 1 & 60 & 2 & & & & & & 7 & \\
\hline United Kingdom & 1 & & 173 & 1 & & & & & & 4 & 1 \\
\hline France & 1 & 3 & 149 & 5 & 2 & 2 & & 5 & 2 & 32 & 9 \\
\hline Ireland & & & 4 & & & & & & & 3 & \\
\hline Netherlands & & & 25 & & & & & & & 10 & \\
\hline Switzerland & & & 7 & & & & & & & & \\
\hline Germany & & 1 & 323 & 3 & 1 & 7 & 1 & & 1 & 53 & 5 \\
\hline Austria & & 1 & 101 & 1 & & & & 1 & & 2 & \\
\hline Italy & & 3 & 184 & 1 & 4 & 5 & & 3 & 4 & 60 & 2 \\
\hline Malta & 5 & 2 & 78 & 4 & & 7 & & & & 17 & 3 \\
\hline Portugal & 1 & 4 & 498 & 11 & 2 & & & 4 & & 42 & 4 \\
\hline Spain & 14 & 3 & 4,891 & 100 & 16 & 17 & 16 & 34 & 6 & 446 & 78 \\
\hline Greece & 8 & 31 & 1,315 & 39 & 11 & 23 & 19 & 21 & 2 & 156 & 36 \\
\hline Baltic countries & & & 143 & 1 & & 1 & & & & 1 & \\
\hline Bulgaria & 10 & & 350 & 5 & 3 & 3 & 4 & & 1 & 90 & \\
\hline Poland & 1 & & 510 & 49 & & 4 & 1 & 2 & 4 & 18 & 4 \\
\hline Romania & & & 19 & 2 & & & & & & 15 & \\
\hline Czech Rep. + Slovakia & 5 & & 290 & 1 & 1 & 8 & & & 4 & 16 & \\
\hline Hungary & 2 & 7 & 164 & 16 & & 5 & & & 14 & 8 & 5 \\
\hline Cyprus & 2 & 80 & 202 & 26 & 10 & 17 & 3 & 1 & 1 & 81 & 20 \\
\hline Turkey & 94 & 6 & 674 & 17 & 1 & 6 & 17 & 4 & & 58 & 210 \\
\hline Total & 147 & 143 & 10,637 & 289 & 52 & $12 \mid$ & 63 & 79 & 41 & 1,203 & 383 \\
\hline
\end{tabular}




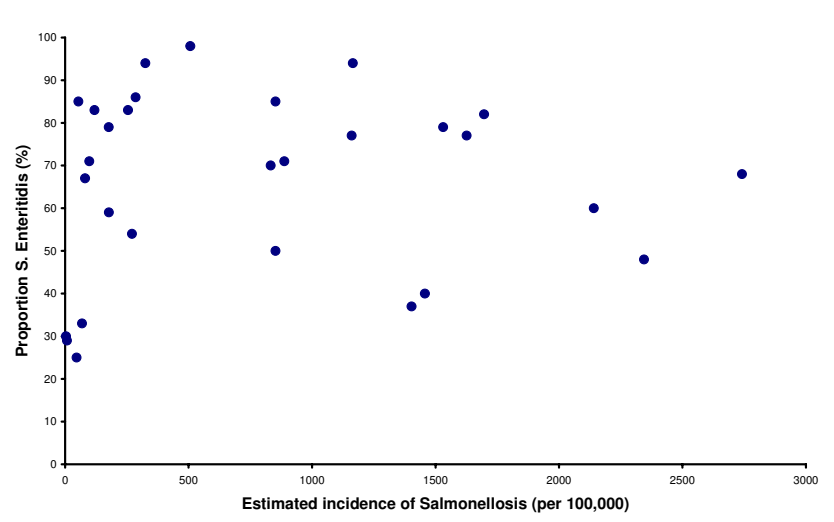

Figure I

Proportion of Salmonella Enteritidis in returning travellers, plotted against the estimated incidence of salmonellosis. Proportion of Salmonella Enteritidis in returning travellers, plotted against the estimated incidence of salmonellosis. Each dot represents one country in the study.

cation database extracted for this study does not contain any information that could be linked to a specific person. The Ethical Committee of the Karolinska Institute, Stockholm, Sweden, approved the study.

\section{Results}

\section{Travel pattern}

Data from the 14,171 respondents in the TDB with recent overnight travel to different European countries/regions during the study period 1997-2003 were weighted and projected to give an estimate of the number of journeys to each European country/region. According to these estimates, Swedish travellers did approximately 60 million overnight journeys to other European countries (78\% leisure trips and $22 \%$ business trips) during the period.

\section{Salmonellosis in returning travellers}

For the study period 1997-2003, altogether 15,864 patients were notified with a salmonella infection after a journey in Europe and out of them 10,607 had an infection caused by $S$. Enteritidis. No cases of salmonellosis were reported among travellers from Luxembourg and Liechtenstein.

The total risk of being notified with salmonellosis was 26.2/100,000 travellers. The lowest risk was seen after a journey to Norway $(0.2 / 100,000$ travellers $)$ followed by Finland (0.4/100,000 travellers) and Norway was hence used as reference. The highest risks was observed in travellers returning from Bulgaria (129/100,000 travellers), Turkey (110/100,000 travellers and Malta (101/100,000 travellers) (Table 1).
The total risk of being notified with a salmonella infection caused by $S$. Enteritidis, all phage types, was $17.5 / 100,000$ travellers. The highest risks were seen for traveling in Bulgaria with 87.5/ 100,000 travellers, Portugal 66.4/ 100,000 travellers, and Turkey 53/100,000 travellers, data not shown.

\section{Disease burden}

When using our data to estimate the actual incidence of salmonellosis, the incidence varied from 4/100,000 inhabitants in Norway up to $2,741 / 100,000$ inhabitants in Bulgaria (Table 1). Countries with the lowest burden of disease were situated in the northern parts of Europe while countries with a higher burden were situated in the southern parts of Europe. Poland is the only country in the northern part that had a high burden of disease. Countries in the eastern parts of Europe also tended to have a higher burden than the countries situated in the western parts of Europe.

\section{Serovar distribution}

Details on the different serovars of Salmonella, clearly showed the relative high burden of $S$. Enteritidis in Europe, accounting for $67 \%$ of the cases. However, the proportion of $S$. Enteritidis cases from the different countries varied from 25\% (Iceland) up to $98 \%$ (Latvia). The second most frequent serovar was $S$. Typhimurium accounting for $9 \%$ of the cases (Table 2). When plotting the proportion of $S$. Enteritidis in returning travellers against the estimated incidence no correlation could be detected (Figure 1).

\section{Phage type distribution of S. Enteritidis}

Of the 10,607 cases of $S$. Enteritidis in our database, data on phage type (PT) was available for 10,479 (99\%) cases. In all, 48 different phage types were represented among the notified cases during the study period. Regional variations in serovar distribution could be noted. $S$. Enteritidis PT 4 is the most dominating phage type, accounting for $35 \%$ of all $S$. Enteritidis cases, while PT 1 accounts for $22 \%$. On the Iberian Peninsula and in some eastern parts of Europe PT 1 is the dominating phage type, while PT $14 \mathrm{~b}$ is dominating in Greece and PT 8 in Czech Republic, Denmark and Slovakia, (Table 3). Spain is the only European country having persons returning with PT 44 (28 cases). An outbreak with PT 34 in Denmark caused 73 cases and this phage type is also reported from Spanish travellers.

\section{Duration of stay}

In the TBD the duration of stay is measured in number of night spent abroad. Figure 4 shows the percentage of night spent in each country. There are differences in the duration of stay, which is correlated to the distance to each country and the accessibility. The duration of stay is not 
Table 3: The number per country of the most common Salmonella Enteritidis phage types in returning Swedish travellers with nontyphoidal salmonellosis 1997-2003.

\begin{tabular}{|c|c|c|c|c|c|c|c|c|c|}
\hline \multirow[b]{2}{*}{ Country } & \multicolumn{9}{|c|}{ Phage types } \\
\hline & $\mathbf{I}$ & 4 & 6 & $6 a$ & $6 b$ & 8 & $13 a$ & I4b & 21 \\
\hline Norway & & & & & & 2 & & & \\
\hline Finland & 5 & & & & & 2 & & & 1 \\
\hline Denmark & 6 & 23 & 52 & 2 & & 61 & 2 & & 7 \\
\hline Iceland & & 1 & & & & & & & \\
\hline Belgium & 2 & 34 & & 5 & & & & 6 & 10 \\
\hline United Kingdom & 10 & 110 & 14 & 6 & & 5 & 4 & 3 & 3 \\
\hline France & 8 & 75 & 12 & 8 & 1 & 18 & & & 3 \\
\hline Ireland & & 4 & & & & & & & \\
\hline Netherlands & & 18 & & 2 & 1 & & & 1 & 2 \\
\hline Switzerland & & 5 & & & & 2 & & & \\
\hline Germany & 10 & 196 & 25 & 9 & & 37 & I & 4 & 20 \\
\hline Austria & 1 & 46 & 4 & & & 35 & 4 & 1 & 2 \\
\hline Italy & 24 & 75 & 3 & 2 & & 24 & 2 & 20 & 14 \\
\hline Malta & & 18 & & 58 & & & & 1 & 1 \\
\hline Portugal & 201 & 96 & 8 & 46 & 2 & & & 39 & 25 \\
\hline Spain & 1,689 & 1,612 & 128 & 211 & 11 & 86 & 20 & 76 & 151 \\
\hline Greece & 139 & 328 & 4 & 120 & 36 & 24 & 3 & 380 & 73 \\
\hline Baltic countries & 77 & 20 & 7 & & & 2 & & & 9 \\
\hline Bulgaria & 7 & 191 & 2 & 2 & 1 & 26 & 15 & 39 & 36 \\
\hline Poland & 43 & 183 & 65 & 2 & I & 101 & & 1 & 84 \\
\hline Rumania & 2 & 9 & I & & & 1 & & I & I \\
\hline Czech Republic + Slovakia & 6 & 33 & 12 & 1 & & 206 & 5 & 2 & 11 \\
\hline Hungary & 4 & 73 & 30 & & & 34 & 1 & 5 & 1 \\
\hline Cyprus & 79 & 71 & 2 & 2 & & 1 & & 7 & 1 \\
\hline Turkey & 20 & 377 & 73 & 8 & & 3 & & 2 & 52 \\
\hline Total & 2,263 & 3,713 & 450 & 489 & 54 & 694 & 69 & 588 & 519 \\
\hline
\end{tabular}

available in the notification from the physician seeing the case of salmonellosis.

\section{Discussion}

To measure the burden of non-typhoidal salmonellosis in different countries using the reported cases in each country will not produce comparable numbers, since the reporting systems in the different European countries are very disparate. In some countries all cases are reported, while in some other countries just the hospitalized cases. Furthermore, in many countries indigenous and imported cases are not considered separately.

To get comparable data, we used a different approach, basing our estimates on returning travellers to Sweden. Reliable denominator data on travel are essential when using travel-related disease data for calculations of risks [18]. The TDB database gives information on each country/region visited with at least one overnight stay (with information obtained directly from the travellers), providing us with a unique opportunity to relate surveillance data to a better-suited travel denominator when calculating the burden of salmonellosis in European countries. This database has previously been used for estimating the risk of travel-related diseases in various parts of the world $[9,19-23]$, and the strengths and limitations of using this approach has been discussed in detail in these articles.

As the numerator we used the notifications in the national surveillance system. Since Sweden has a uniform national system for reporting infectious diseases and the notification database rests on both clinical and laboratory notifications, the sensitivity of the notification system is comparatively good. Using the capture-recapture technique to estimate the proportion of cases being reported by either clinicians or laboratories, more than 99 percent of all diagnosed Salmonella infections were found to be reported each year in 1998 to 2002 [24]. Even with a good notification system, the reported cases likely only represent the tip of the iceberg. Salmonellosis is an acute, mostly self-limited disease, and most cases never come under the attention of a physician, and even less are microbiologically investigated. This however, should not in any major way affect how the countries in this study compare to each other.

The data presented in this study are based on Swedish travellers and their behaviours and risks could never be 
Table 4: Duration of travel shown as percentage of nights spent in each country

\begin{tabular}{|c|c|c|c|c|c|c|c|c|c|c|c|c|c|}
\hline \multirow[b]{2}{*}{ Country } & \multicolumn{13}{|c|}{ Number of nights } \\
\hline & $\mathbf{I}$ & 2 & 3 & 4 & 5 & 6 & 7 & 8 & 9 & 10 & $11-17$ & $18-24$ & $>24$ \\
\hline Norway & 23 & 20 & 14 & 14 & 6 & 7 & 5 & I & 2 & I & 4 & I & 1 \\
\hline Finland & 35 & 25 & 9 & 5 & 4 & 3 & 4 & 2 & 1 & 2 & 5 & 2 & 1 \\
\hline Iceland & 0 & 6 & 26 & 8 & 15 & 8 & 7 & 4 & 9 & 0 & 12 & 5 & I \\
\hline Estonia & 14 & 44 & 13 & 5 & 4 & 1 & 8 & 2 & 2 & 2 & 3 & I & I \\
\hline Ireland & 6 & 9 & 17 & 15 & 12 & 18 & 11 & 3 & 0 & 3 & 5 & 1 & 1 \\
\hline Denmark & 31 & 30 & 15 & 7 & 5 & 4 & 4 & 1 & 1 & 1 & 2 & 1 & 1 \\
\hline Netherlands & 21 & 23 & 16 & 15 & 5 & 6 & I & 2 & 3 & I & 5 & 2 & I \\
\hline United Kingdom & 8 & 17 & 21 & 16 & 9 & 7 & 6 & 3 & 2 & 2 & 6 & 2 & 2 \\
\hline France & 6 & 7 & 9 & 9 & 7 & II & 14 & 6 & 1 & 5 & 16 & 4 & 3 \\
\hline Germany & 21 & 27 & 19 & 9 & 6 & 5 & 3 & 2 & I & I & 5 & I & I \\
\hline Austria & 3 & 3 & 9 & 5 & 10 & 12 & 21 & 8 & 6 & 7 & 11 & 2 & 2 \\
\hline Italy & 1 & 12 & II & 6 & 5 & 12 & 13 & 5 & 3 & 4 & 20 & 4 & 3 \\
\hline Belgium & 26 & 18 & 17 & 15 & 5 & 4 & 8 & 3 & 1 & I & 2 & 1 & $\mathrm{I}$ \\
\hline Lithuania & 2 & 25 & 35 & 18 & 13 & 4 & 0 & 0 & 0 & 2 & 0 & 0 & 2 \\
\hline Latvia & 2 & 26 & 24 & 21 & 17 & 2 & 3 & I & 1 & I & 2 & 0 & 0 \\
\hline Greece & 0 & 1 & 1 & 1 & 2 & 23 & 38 & 2 & I & I & 29 & 2 & 1 \\
\hline Slovenia & 0 & 4 & 8 & 0 & 4 & 0 & 0 & 4 & 0 & 0 & 42 & 15 & 23 \\
\hline Hungary & I & 11 & 16 & 15 & II & 5 & 7 & 3 & I & 3 & 10 & 8 & 9 \\
\hline Czech Republic & 1 & 9 & 27 & 26 & 12 & 10 & 6 & 2 & I & 3 & 2 & 0 & 0 \\
\hline Slovakia & 14 & 21 & 0 & 0 & 0 & 0 & 7 & 7 & 0 & 7 & 0 & 0 & 43 \\
\hline Cyprus & 0 & 0 & 0 & 0 & 2 & 21 & 49 & I & I & 0 & 24 & I & 2 \\
\hline Romania & 4 & 4 & 5 & 4 & 5 & 22 & 29 & 4 & 1 & 2 & 17 & 1 & 2 \\
\hline Spain & 1 & 2 & 3 & 3 & 2 & 20 & 32 & 3 & 2 & 2 & 23 & 3 & 3 \\
\hline Poland & 16 & 27 & 13 & 9 & 8 & 2 & 7 & 2 & 3 & 3 & 6 & I & $\mathrm{I}$ \\
\hline Portugal & 5 & 2 & 6 & 4 & 6 & 23 & 29 & 4 & 0 & 2 & 17 & 1 & 2 \\
\hline Malta & 0 & 0 & 6 & 3 & 6 & 25 & 28 & 3 & 2 & 0 & 5 & 22 & 2 \\
\hline Turkey & 0 & 0 & 4 & 3 & 1 & 21 & 30 & 2 & 0 & 1 & 33 & 3 & 2 \\
\hline Bulgaria & 0 & 0 & 6 & 1 & 0 & 22 & 40 & 5 & 0 & 0 & 25 & 1 & 2 \\
\hline
\end{tabular}

fully representative for those of the native population in the respective countries. The risk estimates are also biased towards the parts of the countries with most tourists. However, since the data concerning the different countries are based on the same methods, we believe the risks estimates for the countries from this study are more suited for comparisons than the reported national incidence figures from the notification systems - with different structures and quality. Furthermore, a study from the UK estimated the incidence of salmonellosis presenting to general practitioners in 1995 to 157 per 100,000 and the incidence of laboratory confirmed cases to 80 per 100,000 [25], figures in the same magnitude as our estimate of 119 per 100,000 in that country.

In this study certain countries in Europe stood out as having a comparatively very high burden of non-typhoidal salmonellosis. A north-south gradient could be clearly distinguished, with increasing incidences the more south in Europe the country is situated. Also a west-east gradient is shown with a higher burden in eastern countries/ regions. Being the most common serovar in most regions of the world, $S$. Enteritidis is especially dominating in Europe, where almost $67 \%$ of all salmonellosis were due to this serovar. In Africa, Asia and America, this serovar has been less dominating and the variety of circulating serovars greater [9].

The duration of travel may affect the risk per 100,000 travellers since persons going to southern countries are mostly on a leisure trip with a longer duration compared to trips to neighbouring countries and thereby the risk for these southern countries could be overestimated. In this study the 4 countries with the highest burden of non-typhoidal salmonellosis were tourist destinations where Swedish travellers mostly stay 1-2 weeks. However, the country with the fifth highest burden, Poland, had travel durations similar to other neighbouring countries of Sweden. This indicates that our method is useful, but improvements can be introduced if duration of stay for the infected traveller is obtainable.

The sometimes very large differences between the estimated disease burden from this study, and the reported figures from the single countries are problematic from public health point of view, therefore the strategy on the future European-level surveillance presented by the ECDC 
in October emphasized the needs for more comparable surveillance data,.

Due to very rigorous control methods in the agricultural area, Sweden has an extremely low domestic incidence of salmonellosis in humans and well as in animals $[26,27]$; less than $0.1 \%$ of food-producing animals are found to carry Salmonella [26]. This favourable situation is shared with the EU member state Finland and the associated countries Iceland and Norway. These four countries have also managed to keep free from the pandemic of egg-associated $S$. Enteritidis that is contributing to a great extent to the burden of salmonellosis in other European countries. At least $75 \%$ of all notified episodes of salmonellosis in Sweden are travel-related. Even in neighbouring Denmark, the situation is the reversed, with only $25 \%$ of the most common serovar, $S$. Enteritidis being related to travel [28]. When becoming members of the EU, Sweden together with Finland received specific Salmonella guarantees, which states that fresh beef, veal and pig meat together with poultry meat should be tested for the presence of Salmonella bacteria before importation. If any serovar of Salmonella is found, importation is not allowed. These guarantees have contributed to the maintenance of the excellent Salmonella situation in these member states and other states may apply for similar guarantees when they have approved control programmes in the agricultural area. Our study shows that these guarantees have a positive effect on public health, resulting in a very low level of indigenous cases of salmonellosis.

The two most common serovars, $S$. Enteritidis and $S$. Typhimurium, are well known to have different animals as reservoir for the disease in Europe. $S$. Enteritidis is shown to be the most frequent serovar isolated from poultry and poultry products including table eggs, while $S$. Typhimurium is the most frequent serovar in pigs, pork, beef and veal. In cattle S. Dublin is the most frequent isolated serovar but $\mathrm{S}$. Typhimurium is the next frequent serovar. [29]. However, S. Typhimurium is also rather common in poultry and $S$. Enteritidis is isolated from beef and pork.

\section{Conclusion}

Our data shows that focusing prevention of salmonellosis to prevention of $S$. Enteritidis infection will have a major impact from a public health perspective and will significantly lower the burden of salmonellosis in most European countries. $S$. Enteritidis is well known to originate from poultry products and products prepared with raw shell eggs. Aiming at reducing the presence of $S$. Enteritidis in poultry products and eggs will have a positive sideeffect since not only $S$. Enteritidis will be reduced but also other serotypes of Salmonella present in these products resulting in an even lower burden of salmonellosis in
Europe. However, since there was no direct correlation between the proportion of $S$. Enteritidis and the estimated overall incidence of salmonellosis, also other actions than those directed against infected poultry and eggs are needed to get down the burden of salmonellosis in those countries with the highest incidence. The new ECDC has identified zoonoses as one of its main priorities, and will together with the EU Member States, the European Commission and the European Food Safety Agency (EFSA) play a pivotal role in the future actions against salmonellosis in Europe.

\section{Competing interests}

The author(s) declare that they have no competing interests.

\section{Authors' contributions}

Both authors participated in the design of the study, performed the calculations and drafted the manuscript. Both authors has read and approved the final manuscript.

\section{Acknowledgements}

The Swedish Institute for Infectious Disease Control funded the study. At the time of planning this study, Karl Ekdahl was working at the Swedish Institute for Infectious Disease Control.

\section{References}

I. Voetsch AC, Van Gilder T], Angulo FJ, Farley MM, Shallow S, Marcus R, Cieslak PR, Deneen VC, Tauxe RV: FoodNet estimate of the burden of illness caused by nontyphoidal Salmonella infections in the United States. CID 2004, 38(suppl 3):SI 27-34.

2. Adak GK, Long SM, O'Brien SJ: Trends in indigenous foodborne disease and deaths, England and Wales: 1992 to 2000. Gut 2002, 5 I:832-84I.

3. Blaser MJ, Newman LS: A review of human salmonellosis: I. Infective dose. Rev Infect Dis 1982, 4: 1096-I 06.

4. D'Aoust JY: Infective dose of Salmonella typhimurium in cheddar cheese. Am J Epidemiol 1985, 1 22:717-20.

5. Miller SI, Hohmann EL, Pegues DA: Salmonella (including Salmonella typhi). In Principles and pratice of infectious diseases 4th edition. Edited by: Mandell GL, Bennett JE, Dolin R. New York: Churchill Livingstone; 1995.

6. Saphra I, Winter JW: Clinical manifestations of salmonellosis in man: an evaluation of $\mathbf{7 7 7 9}$ human infections identified at the New York Salmonella Center. N Engl J Med 1957, 256: I I 28.

7. Buchwald DS, Blaser MJ: A review of human salmonellosis: II. Duration of excretion following infection with nontyphi Salmonella. Rev Infect Dis 1984, 6:345-56.

8. Popoff Y: Antigenic formulas of the Salmonella serovars, $8^{\text {th }}$ revision. WHO Collaborating Centre for Reference and Research on Salmonella, Institut Pasteur, Paris; 2001.

9. Ekdahl K, de Jong B, Wollin R, Andersson Y: Travel-associated non-typhoidal salmonellosis - geographical and seasonal differences and serotype distribution. Clin Microbiol Infect 2005, II:I38-| 44 .

10. WHO Surveillance programme for control of foodborne infections and intoxications in Europe, sixth report 19901992. Berlin 1995.

II. Parker-Baird AC: Foodborne salmonellosis. Lancet 1990, 336: $1231-5$.

12. Chin J, (ed): Control of communicable diseases manual. 17th edition. Washington DC: American Public Health Association; 2000.

13. European Commission: Directive 2003/99/EC of the European Parliament and of the Council of 17 November 2003 on the monitoring of zoonoses and zoonotic agents, amending Council Decision 90/424/EEC and repealing Council Directive 92/II 7/EEC [http://europa.eu.int/smart- 
apcgi/sga doc?smartapi!celexapi!prod!CELEXnumdoc\&lg=EN\&num doc $=32003$ L0099\&model $=$ guichett $]$

14. European Commission: Regulation (EC) No 2160/2003 of the European Parliament and of the Council of 17 November 2003 on the control of salmonella and other specified food-borne zoonotic agents [http:europa.eu.int/smartapi/cgi/ sga doc!smartapi!celexapi!prod!CELEX numdoc\&lg=EN\&numdoc $=32003 R 2160 \&$ model $=$ guichett $]$.

I5. Ekdahl K, Giesecke J: Travellers returning to Sweden as sentinels for true disease incidence in other European countries campylobacter and giardia infection as examples. Euro Surveill 2004, 9:3-4.

16. Swedish Travel and Tourist Data Base, TDB. Resurs AB, Sweden [http://www.resursab.se/]

17. Ward LR, de Sa JDH, Rowe B: A phage-typing scheme for Salmonella Enteritidis. Epidem Inf 1987, 99:291-94.

18. National Travel Health Network and Centre: Illness in England, Wales, and Northern Ireland associated with foreign travel. A baseline report to 20022004 [http://www.hpa.org.uk/infections/topics az/travel/pdf/ full version.pdf]. London: Health Protection Agency

19. Lindbäck H, Lindbäck J, Tegnell A, Janzon R, Vene S, Ekdahl K: Dengue fever in travellers to the Tropics, 1998 and 1999. Emerg Infect Dis 2003, 9:438-42.

20. Ekdahl K, Andersson Y: Regional risks and seasonality in travelassociated campylobacteriosis. BMC Infect Dis 2004, 4:54.

21. Ekdahl K, Andersson Y: Imported giardiasis: impact of international travel, immigration and adoption. Am J Trop Med Hyg 2005, 72:825-30.

22. Ekdahl K, Andersson $\mathrm{Y}$ : The epidemiology of travel-associated shigellosis - regional risks, seasonality and serogroups. J Infect 2005, 5 I:222-9.

23. Ekdahl $\mathrm{K}$, de Jong, Andersson $\mathrm{Y}$ : The risk of travel-associated typhoid and paratyphoid fever in various regions of the world. I Travel Med 2005, I 2:197-204.

24. Jansson A, Arneborn M, Ekdahl K: Sensitivity of the Swedish statutory surveillance for communicable diseases 1998-2002, assessed by the capture-recapture method. Epidemiol Infect 2005, I33:40I-7.

25. Wheeler JG, Sethi D, Cowden JM, Wall PG, Rodrigues LC, Tompkins DS, Hudson MJ, Roderick PJ: Study of infectious intestinal disease in England: rates in the community, presenting to general practice, and reported to national surveillance. The Infectious Intestinal Disease Study Executive. BM] 1999, 3 1 8: 1046-50.

26. Zoonoses in Sweden 2003. Uppsala: National Veterinary Institute (NVI); 2004.

27. Wierup M, Engstrom B, Engvall A, Wahlstrom H: Control of Salmonella Enteritidis in Sweden. Int J Food Microbiol 1995, 25:219-26.

28. Mølback K, Neimann J: Risk factors for sporadic infection with Salmonella Enteritidis, Denmark, 1997-1999. Am J Epidemiol 2002, I 56:654-6I.

29. European Commission: Trends and sources of zoonotic agents in animals, feedingstuffs, food and man in the European Union and Norway in 2002 [http://europa.eu.int/comm/food/food/biosafety/salmonella/ 03 salm 2002.pdf].

\section{Pre-publication history}

The pre-publication history for this paper can be accessed here:

http://www.biomedcentral.com/1471-2458/6/4/prepub 